\title{
Peritoneal carcinomatosis index as a predictor of diaphragmatic involvement in stage III and IV ovarian cancer
}

This article was published in the following Dove Press journal:

OncoTargets and Therapy

\author{
Antoni Lluecal-3 \\ Anna Serra ${ }^{1-3}$ \\ José Luis Herraiz ${ }^{2}$ \\ Isabel Rivadulla ${ }^{1,4}$ \\ Luis Gomez-Quiles ${ }^{1,4}$ \\ Juan Gilabert-Estelles ${ }^{5,6}$ \\ Javier Escrig ${ }^{1,3,4}$
}

On behalf of the MUAPOS

(Multidisciplinary Unit of

Abdominal Pelvic Oncology

Surgery) working group

'Multidisciplinary Unit of Abdominal

Pelvic Oncology Surgery (MUAPOS),

University General Hospital

of Castellón, Castellón, Spain;

${ }^{2}$ Department of Obstetrics and

Gynecology, University General

Hospital of Castellón, Castellón, Spain

${ }^{3}$ Department of Medicine, Universitat

Jaume I, Castellón, Spain; ${ }^{4}$ Department

of General Surgery, University

General Hospital of Castellón,

Castellón, Spain; ${ }^{5}$ Department of

Obstetrics and Gynecology, University

General Hospital of Valencia,

Valencia, Spain; ${ }^{6}$ Department of

Pediatrics, Obstetrics and Gynecology,

University of Valencia, Valencia, Spain

Correspondence: Antoni Llueca Multidisciplinary Unit of Abdominal Pelvic Oncology Surgery (MUAPOS), University General Hospital of Castellón, Av Benicasim, 12004 Castellón, Spain

Tel +34964726500

Email antonillueca@gmail.com
Objective: To analyze the surgical outcomes and diaphragmatic involvement in stage III and IV ovarian cancer.

Patients and methods: All patients with stage III-IV ovarian cancer between January 2013 and January 2016 were included. The outcomes of interest reviewed were as follows: surgical (complications, mortality), peritoneal carcinomatosis index (PCI), rate of complete resection, and disease-free interval and survival.

Results: Fifty-seven patients were included, 38 (67\%) with diaphragmatic involvement; in 10 cases (18\%), diaphragmatic resection was required. Optimal cytoreduction (OCR) was obtained in 49 cases $(86 \%)$. The PCI was $>10$ in 31 cases $(54 \%)$. Respiratory complications occurred in 10 cases $(18 \%)$ and mortality in $3(5 \%)$. Disease-free survival rate in 3 years was $53 \%$, being $87 \%$ in cases without diaphragmatic involvement. The overall survival rate in 3 years is $46 \%, 83 \%$ in the cases without diaphragmatic involvement and $27 \%$ in cases with affectation $(p<0.05)$. In cases of OCR, 3 year survival rate was $65 \%$. In the multivariate analysis for the overall survival of cases with OCR, the only independent prognostic factor found was the operative PCI. A strong correlation was found between the total PCI and the diaphragmatic PCI $(p<0.001)$. With a PCI $>10$, virtually all cases will present diaphragmatic involvement $(p<0.05)$.

Conclusion: The tumor burden is different in stages III and IV of advanced ovarian cancer and the PCI is an effective method to quantify it. The PCI constitutes an independent prognostic factor for the advanced stages of ovarian cancer. A PCI $>10$ constitutes a useful prognostic factor of the affectation and forces the surgeon to thoroughly review both diaphragms.

Keywords: advanced ovarian cancer, peritoneal cancer index, diaphragmatic involvement, upper abdominal surgery, carcinomatosis

\section{Introduction}

Ovarian cancer in its early stages is asymptomatic, which explains why its early detection is uncommon. Thus, most of the cases are diagnosed in advanced stages (III and IV) of the International Federation of Gynecology and Obstetrics (FIGO) staging, turning it into a cancer with a low survival and a high mortality rate. ${ }^{1}$

Numerous studies on prognostic factors have shown the clear benefit of cytoreductive surgery (CR) in these patients, and optimal debulking with no macroscopic evidence of residual tumor is associated with better overall survival in the event of disease spread throughout the peritoneal cavity. ${ }^{2}$

The series published regarding debulking or CR in advanced ovarian cancer demonstrate percentages of cytoreduction ranging between $15 \%$ and $85 \%$. In most of these 
publications, when the percentage of optimal cytoreduction is situated above 50\%, surgical techniques aimed at debulking the upper abdomen, especially the diaphragm, are applied. ${ }^{3,4}$

The aim of this study is to describe the techniques used for diaphragmatic cytoreduction and the prognostic value of the quantification of the PCI, in patients with advanced ovarian cancer and important diaphragmatic involvement, in a tertiary referral hospital for patients with gynecological cancer.

\section{Patients and methods}

From January 2013 to January 2016, a total of 57 patients with advanced ovarian epithelial cancer were eligible for primary debulking surgery and treated in the Multidisciplinary Unit for Abdomino-Pelvic Oncology Surgery (MUAPOS) at the University General Hospital of Castellón. All interventions were performed by the same surgical team. Written informed consent was provided by the patients and the study was approved by Ethics and Clinical Research Committee of our institution.

The classification of the World Health Organization was used for the histological classification. ${ }^{5}$ The histological grade was evaluated according to the criteria of Day et al. ${ }^{6}$ The staging was determined according to the system of the FIGO. ${ }^{7}$ All patients received a mechanical bowel preparation (Citrafleet ${ }^{\circledR}$; Casen Recordati, Zaragoza, Spain) the day before the intervention. Standard antibiotic prophylaxis was carried out with metronidazole 1,500 mg IV and gentamycin $240 \mathrm{mg}$ on the day of the intervention; in addition to the $2 \mathrm{~g}$ of amoxicillin-clavulanic acid IV, which was administered 2 hours prior to surgery. Low-molecularweight heparin, at a standard dose, was administered as thromboembolic prophylaxis, and later continued during the postoperative period. Compression stockings were also used until the patient was ambulating adequately.

All surgeries were carried out under general anesthesia and the abdominal cavity was accessed using a midline xifopubic laparotomy. Sugarbaker's Peritoneal Carcinomatosis Index (PCI) was calculated in all patients at the beginning of surgery. ${ }^{8}$ The scope of the CR surgery carried out in these patients, with the aim of obtaining an optimal cytoreduction (OCR), was related to the spread of the disease and included partial or total resection of the organs affected by the peritoneal dissemination, which is typical of this disease. A peritonectomy of all of the affected peritoneal surfaces, including pelvic and paracolic gutters and abdominal anterior wall, was performed when macroscopic affectation was found. In addition to the basic $\mathrm{CR}$, a diaphragmatic peritonectomy and/or resection was performed in some patients presenting diaphragmatic involvement. On the right side, the diaphragmatic stripping procedure, undertaken in our unit, includes the full mobilization of the right hepatic lobe, permitting a correct display of the diaphragmatic peritoneum, followed by the diaphragmatic peritonectomy, which was performed under a better field of vision (Figure 1). In cases of full-thickness diaphragmatic resection, the diaphragm is reconstructed using interrupted sutures of long-lasting absorbable suture material (Figure 2). A "bubble test" was conducted simultaneously using thoracic hyperpressure maneuvers to verify the effectiveness of the chest closure. A chest tube was not systematically used. All patients underwent chest radiographic controls in the immediate postoperative period to confirm the absence of pneumothorax or pleural effusion.

OCR was defined as residual tumor $<1 \mathrm{~cm}$, complete cytoreduction (CCR) as microscopic tumor residue, and suboptimal cytoreductive surgery as a residual tumor $>1 \mathrm{~cm}$ in diameter. The complications were classified according to the Clavien-Dindo classification; ${ }^{9}$ only the moderately severe high (grade II and III) degrees were taken into account. Respiratory complications included respiratory failure, which required intubation and assisted ventilation; pneumothorax, pneumonia, and pleural effusion, this one needing postoperative drainage. Postoperative mortality was defined as the patient's demise within 30 days of surgery and during their hospital admission. The patients were discharged when oral tolerance was achieved, when both bowel and bladder function had recovered.

Categorical variables are described by the count and relative percentage. Quantitative variables are described by the median and range (minimum-maximum). Mann-Whitney test was used to compare groups of quantitative variables while the Fisher's exact test was used to compare groups of categorical variables. Correlation between quantitative variables

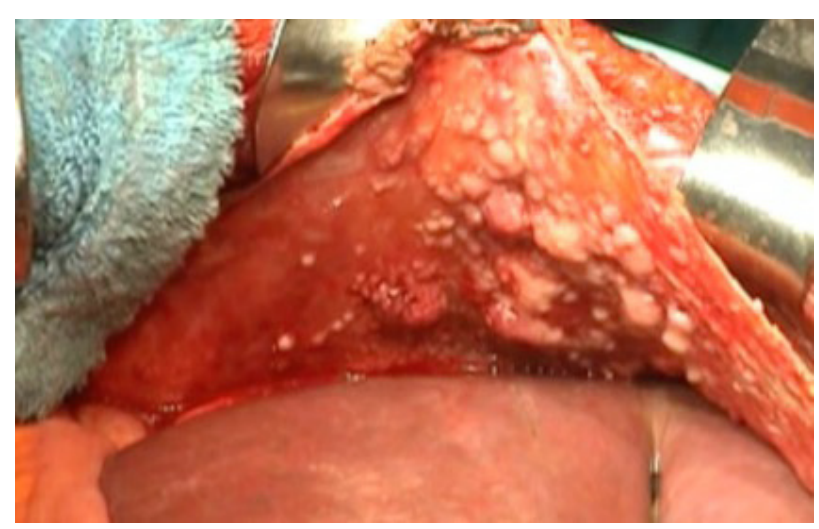

Figure I Diaphragmatic peritonectomy. 

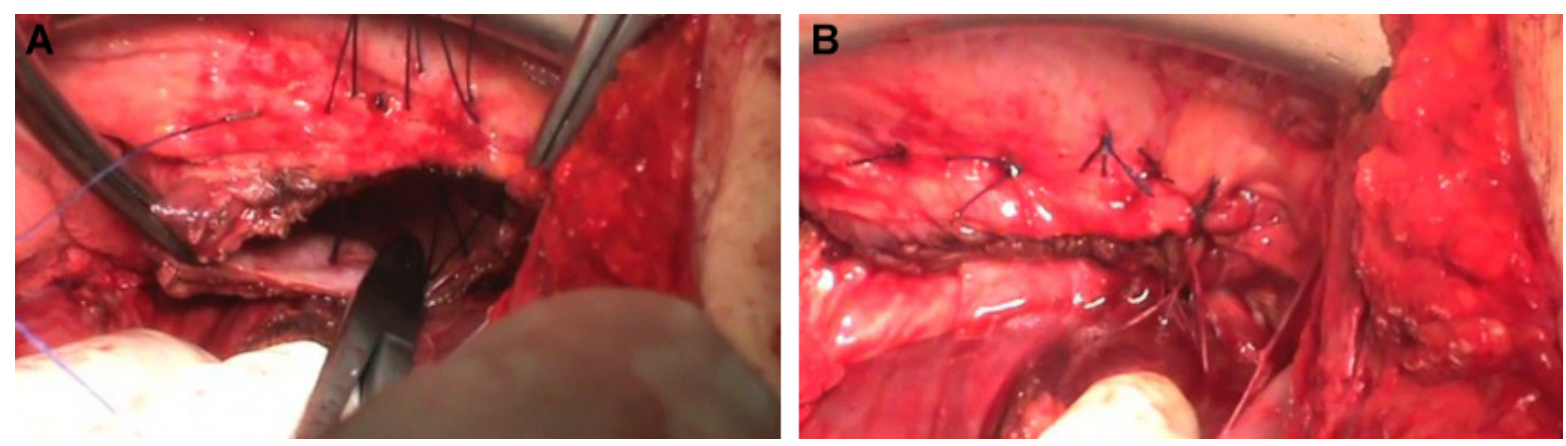

Figure 2 Diaphragmatic reconstruction post-resection.

Note: Diaphragm is reconstructed using interrupted sutures of long-lasting absorbable suture material. Before closing diaphragm (A) and after (B).

was analyzed using the Spearman rho coefficient. KaplanMeier method was used for survival univariate analysis, along with log-rank test for group comparison. Cox' regression was used for survival multivariate analysis. Receiver operating characteristic (ROC) curve was used to discriminate between different diagnostic methods. The statistical analysis was conducted using IBM-SPSS package version 22 .

\section{Results}

The analysis of the 57 patients diagnosed with advanced ovarian cancer and treated in the MUAPOS unit shows a median follow-up of 12 months (10-50). The relationship among the
FIGO stages was the following: one had stage IIIA, another had stage IIIB, 36 patients had stage IIIC, and 19 patients stage IV. Regarding the diaphragmatic affectation, the series of cases is divided into 2 parts: 38 cases presented diaphragmatic involvement (67\%), 10 (18\%) of these cases also required a diaphragmatic resection to achieve OCR. The main characteristics of these patients are summarized in Tables 1 and 2.

In 47 cases $(83 \%)$, a pelvic and aortocava lymphadenectomy was performed with a median of 25 lymph nodes analyzed (4-88), and a median of 2 positive lymph nodes $(0-36)$. The CCR was reached in 49 cases $(86 \%)$,

Table I Diaphragmatic involvement

\begin{tabular}{|c|c|c|c|}
\hline & Yes $(n=38)$ & No $(n=19)$ & Total $(n=57)$ \\
\hline Age (years) & $60(4 I-78)$ & $66(42-78)$ & $6 I(4 I-78)$ \\
\hline CA- 125 & $262(27-14,125)$ & $80(23-15,166)$ & $174(23-15,166)$ \\
\hline Operative PCl & $15(3-33)$ & $3(0-18)$ & $12(0-33)$ \\
\hline \multicolumn{4}{|l|}{ Categorized operative PCI* } \\
\hline $0-10$ & $8(21 \%)$ & 18 (95\%) & $26(46 \%)$ \\
\hline $\mathrm{II}-20$ & $19(50 \%)$ & I (5\%) & $20(35 \%)$ \\
\hline$>20$ & II (29\%) & 0 & II (19\%) \\
\hline \multicolumn{4}{|l|}{ Categorized operative PCI* } \\
\hline$\leq 10$ & $8(21 \%)$ & $18(95 \%)$ & $26(46 \%)$ \\
\hline$>10$ & $30(79 \%)$ & I (5\%) & 31 (54\%) \\
\hline Ascites & $10(26 \%)$ & $4(2 \mid \%)$ & 14 (25\%) \\
\hline \multicolumn{4}{|l|}{ Complications } \\
\hline Total & $21(55 \%)$ & $8(42 \%)$ & $29(51 \%)$ \\
\hline Clavien-Dindo I-II & $10(47 \%)$ & $6(75 \%)$ & $16(55 \%)$ \\
\hline Clavien-Dindo III & $6(28 \%)$ & $2(25 \%)$ & $8(28 \%)$ \\
\hline Clavien-Dindo IV & $5(24 \%)$ & 0 & $5(17 \%)$ \\
\hline Respiratory complications* & $10(26 \%)$ & 0 & $10(18 \%)$ \\
\hline Visceral resections* & $38(100 \%)$ & $10(53 \%)$ & $48(84 \%)$ \\
\hline Diaphragmatic resection* & $10(26 \%)$ & 0 & $10(18 \%)$ \\
\hline Splenectomy* & I8 (47\%) & 0 & $18(32 \%)$ \\
\hline Exitus 90 days & $3(8 \%)$ & 0 & $3(5 \%)$ \\
\hline Disease-free survival at 3 years* & 0.3 & 0.87 & 0.53 \\
\hline Overall survival at 3 years* & 0.27 & 0.83 & 0.46 \\
\hline
\end{tabular}

Note: Median (range); count (\%); ${ }^{p} p<0.05$.

Abbreviations: $\mathrm{CA}$, cancer antigen; $\mathrm{PCl}$, peritoneal cancer index. 
Table 2 Diaphragmatic resection

\begin{tabular}{|c|c|c|c|}
\hline & Yes $(n=10)$ & No $(n=47)$ & Total $(n=57)$ \\
\hline Age (years) & $60(4 I-74)$ & $63(4 I-78)$ & $61(4 \mid-78)$ \\
\hline CA- 125 & $\mid 97(4 \mid-5,688)$ & $166(23-15,166)$ & $174(23-15,166)$ \\
\hline Operative $\mathrm{PCl}^{*}$ & $20(10-33)$ & $10(0-33)$ & $12(0-33)$ \\
\hline \multicolumn{4}{|l|}{ Categorized operative PCI* } \\
\hline$\leq 10$ & $\mathrm{I}(10 \%)$ & $25(53 \%)$ & $26(46 \%)$ \\
\hline$>10$ & $9(90 \%)$ & $22(47 \%)$ & 31 (54\%) \\
\hline Diaphragmatic PCI* & $4(2-6)$ & I (0-6) & $2(0-6)$ \\
\hline Ascites & $3(30 \%)$ & II (23\%) & $14(25 \%)$ \\
\hline \multicolumn{4}{|l|}{ Complications } \\
\hline Total & 7 (70\%) & $22(47 \%)$ & 29 (5I\%) \\
\hline Clavien-Dindo I-II & $4(57 \%)$ & $12(55 \%)$ & $16(55 \%)$ \\
\hline Clavien-Dindo III & $2(29 \%)$ & $6(27 \%)$ & $8(28 \%)$ \\
\hline Clavien-Dindo IV & I (I4\%) & $4(18 \%)$ & $5(17 \%)$ \\
\hline Respiratory complications* & $4(40 \%)$ & $6(12 \%)$ & $10(18 \%)$ \\
\hline Exitus 90 days & $3(30 \%)$ & 0 & $3(5 \%)$ \\
\hline Disease-free survival at 3 years* & 0.42 & 0.59 & 0.53 \\
\hline Overall survival at 3 years* & 0 & 0.58 & 0.46 \\
\hline
\end{tabular}

Note: Median (range); count (\%); ${ }^{*} p<0.05$.

Abbreviations: $\mathrm{CA}$, cancer antigen; $\mathrm{PCl}$, peritoneal cancer index.

OCR in 53 cases (93\%), and an suboptimal cytoreductive surgery was obtained in 4 cases (7\%). The PCI was $>10$ in 31 cases (54\%), 30 of them with diaphragmatic involvement (79\%), and 9 (90\%) with diaphragmatic resection. A total of $18(32 \%)$ splenectomies were performed, all of them in cases of diaphragmatic involvement.

From the total number of complications that occurred in our series, 10 cases were respiratory (18\%), which took place in cases of diaphragmatic affectation. Three postoperative deaths occurred (5\%), the 3 of them being patients with diaphragmatic involvement, and 2 of them underwent diaphragmatic resection. However, such outcomes were not directly related to the diaphragmatic surgery.

Disease-free survival rate in 3 years for the entire series was $53 \%$, being $87 \%$ in cases without diaphragmatic involvement and $30 \%$ in those cases with affectation. The overall survival rate within 3 years was $46 \%, 83 \%$ in the cases without diaphragmatic involvement and $27 \%$ in cases with affectation ( $p<0.05$; Figure 3$)$. When diaphragmatic resection was performed, there were no survivors within the 3-year time, whereas in the patients without diaphragmatic resection, the overall survival was $58 \%(p<0.05)$. When an OCC is not obtained, there were no survivors beyond 26 months. On the other hand, in cases of OCC, survival within 3 years was $65 \%$, although the difference was not statistically significant because there were only 4 cases of suboptimal cytoreduction. In the multivariate analysis for the overall survival of cases with OCC, the only independent prognostic factor found was the operative PCI.
A strong correlation was found between the total PCI and the diaphragmatic PCI, being this one highly statistically significant (Spearman $r=86 \%, p<0.001$ ). The prognosis of diaphragmatic involvement and resection was strongly correlated with the PCI (Figures 4 and 5). For a PCI $>10$, there was only 1 case of false positive diaphragmatic involvement (specificity of 95\%), with a probability of correct

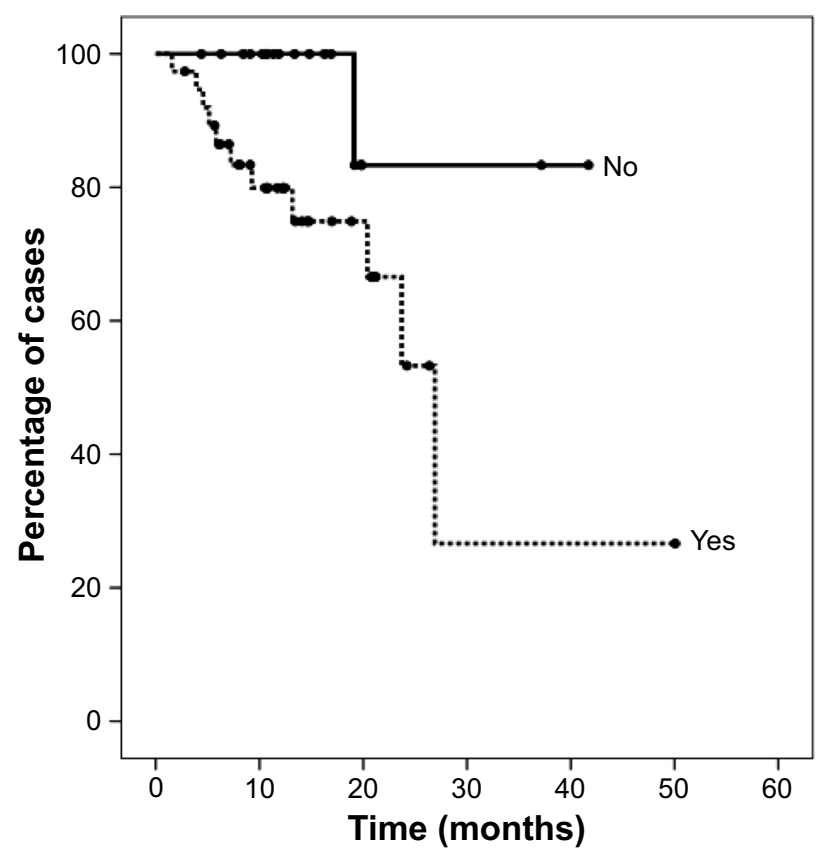

Figure 3 Diaphragmatic involvement: overall survival.

Notes: Diaphragmatic involvement: 38 cases. Without diaphragmatic involvement: 19 cases. 


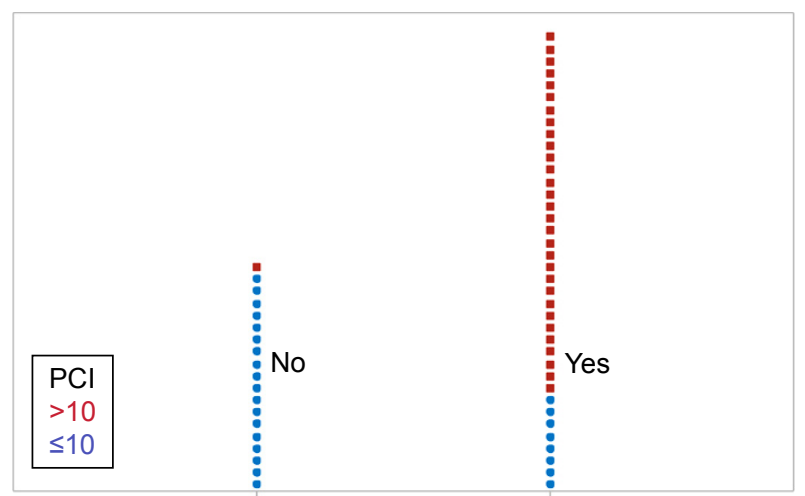

Figure 4 Diaphragmatic involvement: 10 as the cut-off for the $\mathrm{PCl}$.

Notes: Prevalence of involvement: $67 \%$. Sensitivity: 79\% (95\% CI: 63-90). Specificity: $95 \%$ (95\% Cl: $74-99)$. Positive predictive value: $97 \%$. Negative predictive value: $69 \%$ Discrimination (receiver operating characteristic area): $87 \%$.

Abbreviation: $\mathrm{PCl}$, peritoneal cancer index.

discrimination between affectation and non-affectation of $87 \%$ (ROC area). Regarding the prognosis of surgical resection, for a PCI $>10$, only 1 case of false negative of resection result was observed (sensitivity of $90 \%$ ) with a high probability of correct discrimination between resection and non-resection (72\%). This means that with a PCI $>10$, all cases will virtually present diaphragmatic involvement, while in cases of PCI $<10$, the need for a diaphragmatic resection is highly unlikely.

\section{Discussion}

We present a retrospective series of 57 patients treated in our hospital due to advanced ovarian cancer, FIGO stages III and IV. Primary debulking surgery followed by postoperative chemotherapy is the gold standard in the treatment of advanced ovarian cancer. In recent years, the residual tumor volume has been associated with survival in such a way that after CCR (without macroscopic tumor residue) or after OCR $(<1 \mathrm{~cm}$ of residual tumor), there are benefits in terms of survival, unlike the suboptimal or incomplete cytoreduction

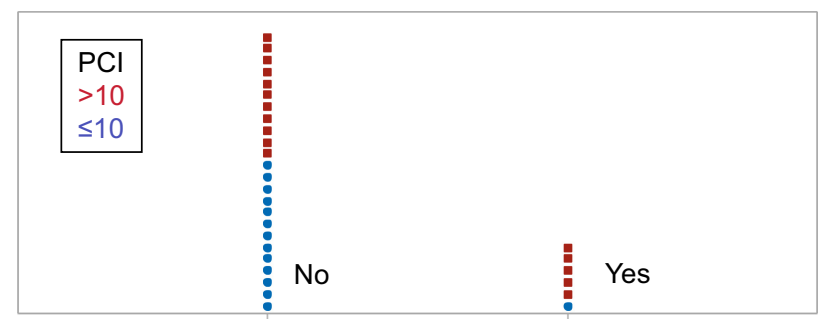

(Every symbol represents up to 2 observations)

Figure 5 Diaphragmatic resection: 10 as cut-off for $\mathrm{PCI}$.

Notes: Prevalence of resection: 18\%. Sensitivity: 90\% (95\% Cl: 56-99). Specificity: 53\% (95\% Cl: 38-68). Positive predictive value: $29 \%$. Negative predictive value: $96 \%$. Discrimination (receiver operating characteristic area): $72 \%$.

Abbreviation: $\mathrm{PCl}$, peritoneal cancer index. (residual tumor $>1 \mathrm{~cm}) .{ }^{10}$ In our series, a CCR was achieved in 49 cases $(86 \%)$ and in 4 cases $(7 \%)$ there was $<1 \mathrm{~cm}$ of residual tumor. In order to achieve these results, we had to apply cytoreduction techniques of the upper abdomen in over $60 \%$ of our cases. These results are similar to those found in other series where the spread of the diaphragmatic tumor appears in more than $40 \%$ of advanced ovarian cancers. ${ }^{11}$ In order to achieve a high percentage of OCR, the oncologic gynecologists must acquire the necessary skills for upper abdominal surgery. ${ }^{12}$

The median of the PCI measured in the surgical exploration in cases of diaphragmatic involvement $(\mathrm{PCI}=15)$ and in cases of resection $(\mathrm{PCI}=20)$ presented a large statistically significant difference, unlike the cases without involvement $(\mathrm{PCI}=3)$ and without resection $(\mathrm{PCI}=10)$. $\mathrm{PCI}$ was $>10$ in $79 \%$ of cases of diaphragmatic affectation and in $90 \%$ of diaphragmatic resection; PCI $<10$ was in $95 \%$ of patients without affectation and in $53 \%$ of patients without resection; these results were also statistically significant. Along with other authors, ${ }^{13}$ we believe that the amount of tumor in the upper abdomen is conditioned by the aggressive biology of the tumor (type 2 ovarian tumors in the carcinogenic models $)^{14}$ and possibly by the evolution of the disease during a large period of time. Although we have neither a variable that can adequately measure the biological aggressiveness of the tumor nor the exact time of evolution, these 2 factors may probably have repercussions over the PCI value, which would act as a surrogate variable with a strong correlation with survival. The strong correlation between the total PCI and the diaphragmatic PCI suggests that the diaphragmatic affectation is merely a marker for the extension of the peritoneal disease.

Significant respiratory complications appeared in 10 cases (18\%), which were much more frequent in those with diaphragmatic involvement and resection. In contrast to other series, our data revealed that respiratory complications were more frequent in cases in which a resection was carried out $(40 \%)$, instead of those in which only a diaphragmatic peritonectomy was performed (26\%). Visceral resections, such as splenectomy, were carried out in all cases of diaphragmatic affectation. As in other series, a high tumor burden forces us to perform multiple visceral resections and in cases of affectation of the left diaphragm, the splenic disease is very frequent. ${ }^{15}$ The total postoperative mortality within 90 days for our series is $5 \%$, all of them with diaphragmatic disease.

The disease-free survival and overall survival within 3 years were significantly better in the cases without diaphragmatic involvement; this fact was associated with a 
lower peritoneal tumor burden. As previously mentioned, we believe that in the cases of diaphragmatic disease, a high tumor load is usually associated along with a greater biological aggressiveness of the tumor, which severely compromises the survival of these patients. ${ }^{13,16}$ In this regard, it is also notable that no patient having undergone suboptimal cytoreduction survived much longer than 2 years compared to the $65 \%$ survival in 3 years in the cases with OCR, despite the fact that $18 \%$ of the latter presented a PCI $>20$. This suggests that the surgical effort made in the OCR group may have possibly participated in the increase of survival, although we were unable to demonstrate this correlation in our current study from a statistical point of view.

It has been noted in our series that a cut-off at 10 for the intraoperative PCI generates an optimal dividing line about the possibility of having to carry out surgical acts on the diaphragm with peritonectomy, or associating a resection of varying size. This will eventually have an impact on the probability of respiratory complications in the postoperative course as well as on the overall survival prognosis. One of the limitations of this study is the retrospective nature of it and another one could be the intraoperative quantification of PCI. From the clinical point of view, the next step should be the possibility of quantifying PCI in preoperative studies and, therefore, the surgeon could be prepared for upper abdominal surgeries when a PCI $>10$ was found. And finally, one of the unanswered questions, is the necessity of performing diaphragmatic peritonectomy even without any macroscopic lesion seen in the intraoperative PCI. Further studies are necessary to evaluate these 2 considerations.

\section{Conclusion}

The tumor load is different for stages III and IV and the PCI is an effective method to quantify it, especially in the advanced stages of ovarian cancer. The diaphragmatic involvement and, above all, the need for resection in order to achieve an OCR are highly correlated with the total intraoperative PCI, which constitutes an independent prognostic factor for the advanced stages of ovarian cancer. On the other hand, a PCI $>10$ constitutes a useful prognostic factor of the affectation and forces the surgeon to thoroughly review both diaphragms. To achieve a CCR, in more than $40 \%$ of the cases, the oncology gynecologist will consequently need to apply specific surgical techniques for the upper abdomen.

\section{Acknowledgments}

We thank Begoña Belles, from University Jaume I (UJI) for editing a draft of this manuscript and Carmen Tauste and Juan Carlos Muruzabal from the Department of Obstetrics and Gynecology in the Hospital Complex of Navarra, Pamplona (Spain) for the final revision of the manuscript. This work received financial support from the Medtronic University Chair for Training and Surgical Research (University Jaume I [UJI], Castellon, Spain). MUAPOS working group (Multidisciplinary Unit of Abdominal Pelvic Oncology Surgery): A Serra-Rubert, L Gomez-Quiles, I Rivadulla, R Játiva-Porcar, E Moreno-Clarí, B Montañés-Pauls, L Granel-Villach, M Bellver, K Maiocchi, C Medina-Medina, K Delgado-Barriga, M Rodrigo-Aliaga, N Ruiz, A Lopez, Y Maazouzi, D Piquer, B Segarra, R Del Moral.

\section{Disclosure}

The authors report no conflicts of interest in this work.

\section{References}

1. Abella Llueca JA, Martinez-Ramos D, Escrig-Sos J, et al. Current status of ovarian cancer in the Spanish Province of Castellon. Prognostic factors in observed and relative survival. A population cancer-registrybased study between 2004 and 2008. Prog Obstet Ginecol. 2014; 57(9):405-412.

2. du Bois A, Reuss A, Pujade-Lauraine E, Harter P, Ray-Coquard I, Pfisterer J. Role of surgical outcome as prognostic factor in advanced epithelial ovarian cancer: a combined exploratory analysis of 3 prospectively randomized phase 3 multicenter trials: by the Arbeitsgemeinschaft Gynaekologische Onkologie Studi-engruppe Ovarialkarzinom (AGOOVAR) and the Groupe d'Investigateurs Nationaux Pour les Etudes des Cancers de l'Ovaire (GINECO). Cancer. 2009;115(6):1234-1244.

3. Bristow RE, Tomacruz RS, Armstrong DK, Trimble EL, Montz FJ. Survival effect of maximal cytoreductive surgery for advanced ovarian carcinoma during the platinum era: a meta-analysis. J Clin Oncol. 2002;20(5):1248-1259.

4. Kuhn W, Florack G, Roder J, et al. The influence of upper abdominal surgery on perioperative morbidity and mortality in patients with advanced ovarian cancer FIGO III and IV. Int J Gynecol Cancer. 1998;8(1):56-63.

5. Serov SF, Scully RE, Sorbin LH. Histological typing of ovarian tumors. In: International Histological Classification of Tumors. Geneva: World Health Organization; 1973;9:17.

6. Day TG, Gallager HS, Rutledge FN. Epithelial carcinoma of the ovary: the prognostic importance of histologic grade. Natl Cancer Inst Monogr. 1975;42:15-21.

7. International Federation of Gynecology and Obstetrics. Changes in definitions of clinical staging for carcinoma of the cervix and ovary. Am J Obstet Gynecol. 1987;156(1):263-264.

8. Esquivel J, Farinetti A, Sugarbaker PH. [Elective surgery in recurrent colon cancer with peritoneal seeding: when not to proceed]. G Chir. 1999;20(3):81-86. Italian.

9. Dindo D, Demartines N, Clavien PA. Classification of surgical complications: a new proposal with evaluation in a cohort of 6336 patients and results of a survey. Ann Surg. 2004;240(2):205-213.

10. Llueca JA, Herraiz JL, Catala C, Serra A, Rivadulla I, Escrig J; MUAPOS Working Group. Effectiveness and safety of cytoreduction surgery in advanced ovarian cancer: initial experience at a University General Hospital. J Clin Gynecol Obstet. 2015;4(3):251-257. 
11. Zivanovic O, Sima CS, Iasonos A, et al. The effect of primary cytoreduction on outcomes of patients with FIGO stage IIIC ovarian cancer stratified by the initial tumor burden in the upper abdomen cephalad to the greater omentum. Gynecol Oncol. 2010;116(3): 351-357.

12. Shin KK, Chi DS, Maximal cytoreductive effort in epithelial ovarian cancer surgery. J Gynecol Oncol. 2010;21(2):75-80.

13. Covens AL. A critique of surgical cytoreduction in advanced ovarian cancer. Gynecol Oncol. 2000;78(3 Pt 1):269-274.

14. Wang F, Wang Y, Zhou Y, et al. Comparison between types I and II epithelial ovarian cancer using histogram analysis of monoexponential, biexponential, and stretched-exponential diffusion models. J Magn Reson Imaging. 2017;46(6):1797-1809.
15. Soleymani Majd H, Ferrari F, Manek S, et al. Diaphragmatic peritonectomy vs. full thickness resection withpleurectomy during Visceral-Peritoneal Debulking (VPD) in 100 consecutive patients with stage IIIC-IV ovarian cancer: a surgical-histological analysis. Gynecol Oncol. 2016;140(3):430-435.

16. Zivanovic O, Sima CS, Iasonos A, et al. The effect of primary cytoreduction on outcomes of patients with FIGO stage IIIC ovarian cancer stratified by the initial tumor burden in the upper abdomen cephalad to the greater omentum. Gynecol Oncol. 2010;116(3):351-357.

\section{Publish your work in this journal}

OncoTargets and Therapy is an international, peer-reviewed, open access journal focusing on the pathological basis of all cancers, potential targets for therapy and treatment protocols employed to improve the management of cancer patients. The journal also focuses on the impact of management programs and new therapeutic agents and protocols on

\section{Dovepress}

patient perspectives such as quality of life, adherence and satisfaction. The manuscript management system is completely online and includes a very quick and fair peer-review system, which is all easy to use. Visit http://www.dovepress.com/testimonials.php to read real quotes from published authors.

Submit your manuscript here: http://www.dovepress.com/oncotargets-and-therapy-journal 